\title{
A PRISÃO PREVENTIVA NO SISTEMA JURÍDICO BRASILEIRO: ENTRE A PROTEÇÃO DO ACUSADO E A ANTECIPAÇÃO DA PENA PRESUMIDA
}

\author{
THE REMAND IN BRAZILIAN LEGAL SYSTEM: BETWEEN \\ THE PROTECTION OF THE ACCUSED AND THE \\ ANTICIPATION OF THE PRESUMED PENALTY
}

RESUMO: O Estado capitalista estabelece uma relação espúria entre a promoção da privação de liberdade e da segurança individual que implica num acirramento do processo de encarceramento. Para abordar esse tema, na primeira parte do texto nos reportamos ao debate de matriz weberiana sobre racionalização e ascensão de uma ordem burocrática como marcas da modernidade. $\mathrm{Na}$ segunda parte descrevemos como o ordenamento jurídico brasileiro projetou a "prisão" enquanto arcabouço legal e aparato institucional. A seguir apresentamos o caso das excessivas prisões preventivas como modelo exemplar de uma reversão do Estado de Direito. Concluímos que o uso indevido da prisão preventiva como antecipação de pena fere os direitos fundamentais levando a consequências como a substituição do poder público pelo crime na gestão do sistema prisional e o reforço à exclusão como tônica do sistema.

Palavras-chave: Prisão preventiva. Max Weber. Burocracia.
ABSTRACT: The capitalist State establishes a spurious relation between the promotion of deprivation of liberty and the individual security that implies a deepening of the process of incarceration. To address this theme, in the first part of the text we refer to the Weberian matrix debate about rationalization and rise of a bureaucratic order as marks of modernity. In the second part, we describe how the Brazilian legal system designed "prison" as a legal framework and institutional apparatus. The following is the case of excessive remand as an exemplary model of a reversal of the rule of law. We conclude that the misuse of remand as an anticipation of punishment violates fundamental rights leading to consequences such as the substitution of public power for crime in the management of the prison system and reinforcement to exclusion as the system's main focus.

Keywords: Remand. Max Weber. Bureaucracy.

\footnotetext{
${ }^{1}$ Professor do quadro permanente da Universidade Federal do Maranhão - UFMA na área de Ciências Sociais. Doutorando em Sociologia pela Universidade Estadual do Ceará.
} 


\section{INTRODUCÃO}

O presente estudo parte do princípio de que o capitalismo é, para além de um sistema econômico, também um sistema social de caráter totalizante. A ascensão da ética burguesa, na perspectiva da análise weberiana, teria como signo maior a transmutação do materialismo em artefato cultural no contexto da modernidade.

O elemento central que permitiria divisar a modernidade seria a ascensão da racionalidade e da racionalização como base sobre a qual se assenta nossa relação com o mundo. A análise social deve incluir na sua agenda a verificação da influência das estruturas sobre o nível da ação do sujeito, mas também o modo como o sujeito decide seu curso de ação e a relação entre a volição individual e a estruturação social.

Nesse sentido ação e relação social emergem como técnicas de convivência, sendo que o sistema prisional se constitui em caso empírico da formação de padrões de interação arbitrários desde sua estrutura até a (sobre)vivência intramuros. A sociedade conservadora erigida pelo capital estabelece uma relação espúria entre a promoção da privação de liberdade e da segurança individual que implica num acirramento do processo de encarceramento, mesmo que à revelia dos institutos legais criados por essa mesma sociedade.

Aqui se torna essencial denunciar a falácia da propaganda sobre a ideia de reabilitação prisional visto que estamos diante de instituições que visam reproduzir a sociedade de classes in natura. Isso se evidencia na dualidade entre repressão e prevenção e a opção sistemática pelo Estado burguês pela primeira.

Caso emblemático dessa racionalidade de Estado no contexto do capitalismo é a manutenção por prazo indeterminado da prisão provisória, a despeito da necessidade legal da mesma ter caráter excepcional e não normal. Neste e em outros casos atinentes ao sistema prisional o que se percebe é a flagrante contradição entre o que se prevê e o que se provê. As consequências são a substituição do poder público pelo crime na gestão do sistema prisional e o reforço à exclusão como tônica do sistema. 
$\mathrm{Na}$ primeira parte do texto iremos nos reportar ao debate de matriz weberiana sobre racionalização e ascensão de uma ordem burocrática como marcas da modernidade. $\mathrm{Na}$ segunda parte descrevemos como o ordenamento jurídico brasileiro projetou a "prisão" enquanto arcabouço legal e aparato institucional. A seguir apresentamos o caso das excessivas prisões preventivas como modelo exemplar de uma reversão do Estado de Direito.

\section{MAX WEBER, RACIONALIZAÇÃO E BUROCRACIA COMO FUNDAMENTOS DA SOCIEDADE MODERNA}

Max Weber admite no seu esquadro teórico como pressuposto fundamental a constatação de que, desde seu nascedouro nas revoluções burguesas, o capitalismo constituiu o fator chave para a compreensão da modernidade em função do seu caráter totalizante. Contudo ele foi além e empenhou-se em entender a lógica cultural que permitiu a ascensão e manutenção do capitalismo enquanto sistema social e não apenas como modo de produção econômico.

O sujeito moderno em Max Weber nasce num ambiente envolvente cuja lógica estruturante é material e materialista, racional e racionalista, e cuja mola mestra é o pensamento burguês e sua criação, o capitalismo. De acordo com Riesebrodt (2012, p. 165-166) o que Max Weber deseja incluir na agenda de pesquisa do campo sociológico é justamente todo o conjunto de variáveis culturais que no escopo do materialismo histórico erigido pelo pensamento marxista havia sido relegado ao segundo plano como epifenômeno do mundo econômico.

Neste sentido é que nos estudos sobre a ética protestante Max Weber postula que o homo oeconomicus não deriva diretamente do processo de acumulação de capital, mas de um advento de uma nova ética, um novo conjunto axiológico que orientará o comportamento dos indivíduos numa quadra burguesa.

Ao adicionar os fatores culturais na explicação do comportamento humano Max Weber romperá com o determinismo material professado pela vulgata marxista, mas não abandonará a perspectiva materialista de análise, como bem a atesta a tese sobre a secularização e desencantamento crescente do mundo moderno, de modo que ao 
contrário de Karl Marx, para o qual o materialismo é o ponto de partida, para Max Weber ele constitui o ponto de chegada: a modernidade é o tempo do reino material. Na ótica de Riesebrodt (2012, p. 167) aqui Max Weber concorda com Karl Marx sobre a natureza da sociedade burguesa, discordando de sua origem e situando a mesma como um cosmo cultural no qual emergem invenções como aquilo que viria a ser chamado de individualismo possessivo ${ }^{2}$.

De acordo com Sell (2014, p. 40-42) no modelo de análise derivado do pensamento weberiano podemos identificar três passos da análise social: o primeiro passo consiste em situar a influência das estruturas sobre o nível da ação do sujeito; o segundo passo diz respeito ao processo de identificar o modo como o sujeito decide seu curso de ação; por fim o terceiro nível implica na junção entre a volição individual e a estruturação social.

Aqui reside um divisor de águas analítico weberiano, na medida em que ao nível do sujeito situam-se os instrumentos que orientam suas ações no plano social, enquanto ao nível da estrutura estão as relações sociais orientadas pela ordem econômica ou política vigente, p. exe., o aparato jurídico implica numa prescrição normativa que informa a performance dos indivíduos em suas relações sociais. A analítica weberiana prevê a investigação sobre os fins da ação, os meios empregados e os valores culturais que formam o tecido social no qual se desenrolam as atividades humanas. Isso fica patente na forma como Max Weber (1999, p. 161) caracteriza o Estado moderno, destacando:

\begin{abstract}
aquela monopolização do emprego legítimo de violência, que culmina no conceito moderno do Estado, como fonte última de toda legitimidade de poderes físicos, e, ao mesmo tempo; aquela racionalização das regras para sua aplicação, que culmina no conceito da ordem jurídica legítima.
\end{abstract}

Para fins de análise de aspecto do sistema penal brasileiro, iremos aqui procurar distinguir os conceitos de racionalidade e racionalização em Max Weber. Na ótica de Sell (2012, p. 153-158) em primeiro lugar é preciso destacar no pensamento weberiano que cada esfera da vida moderna (religião, economia, educação, justiça) produzem sua própria racionalização, mas como vimos anteriormente, o sistema capitalista enquanto ambiente envolvente interfere nas diferentes dimensões da vida na atualidade. Assim podemos

\footnotetext{
${ }^{2}$ Sobre o tema vide "MACPHERSON, C.B. The Political Theory of Possessive Individualism: Hobbes to Locke. Oxford, Oxford University Press, 1962".
} 
distinguir entre um tipo de racionalização que diz respeito a um processo histórico e cultural (a transformação da mentalidade) e a racionalização de cada esfera da vida social em particular, de onde se deriva uma legalidade específica para cada caso, se tratamos de religião, economia, política, etc... visto que a interseção entre essas dimensões não implica na sua justaposição. Veja-se o que Max Weber descreve acerca do campo jurídico:

A necessidade crescente de conhecimentos jurídicos especializados fez surgir o advogado profissional. Estas exigências crescentes de experiência e conhecimentos especializados entre os práticos jurídicos e, com isso, o impulso para a racionalização do direito em geral partem, quase sempre, da importância progressiva da troca de bens e daqueles interessados no direito que nela participam, pois nessa esfera surgem os problemas para cuja solução uma especialização profissional, e isto significa racional, tomou-se uma necessidade imperiosa (WEBER, 1999, p. 85).

Nessa perspectiva verificamos com Weber que somente no campo de uma racionalidade prática é que encontramos o sentido possível da ação passível de ser captado no plano sociológico. Mas qual seria o conteúdo dessa racionalidade prática? Ela não é apenas instrumental no sentido de buscar a justa adequação entre meios e fins; também não é puramente eletiva na medida que seleciona valores para conduzir a escolha dos fins a serem almejados; nem tampouco se resume a uma dimensão normativa na medida que uma variável axiológica intervém sobre a ação. A racionalidade prática se bifurca numa linha formal (escolher e ajustar meios e fins) e outra moral (o esquema normativo vigente):

Obedece-se não à pessoa em virtude de seu direito próprio, mas à regra estatuída, que estabelece ao mesmo tempo a quem e em que medida se deve obedecer. Também quem ordena obedece, ao emitir uma ordem, a uma regra: à "lei" ou "regulamento" de uma norma formalmente abstrata (WEBER, 1956 apud GOHN, 2003, p. 129).

Na tipologia clássica weberiana temos a ação racional com relação a fins, a ação racional com relação a valores, a ação afetiva e ação tradicional. Essa tipologia além de não ser mutuamente excludente (a mesma ação pode conter mais de um sentido) também estabelece uma hierarquia entre o ideal e o efetivo, entre o racional que o mundo moderno coloca como desiderato e a realidade irracional dos valores, tradições e relações de afeto que não podem ser eliminados sob risco de tomar o homem como um ser artificial. Sell (2012, p. 163) nos lembra que ao apontar o curso da história rumo à 
racionalização, Max Weber anota que somos demasiados humanos ${ }^{3}$ e que esse traço incontornável é justamente o ponto a ser analisado pelo prisma sociológico.

$\mathrm{Na}$ tópica da sociedade racionalizada, ganha destaque de acordo com a visão weberiana o termo "técnica", que pode ser entendido como o somatório dos meios que a ação emprega para se efetivar. Sobre a "técnica" se impõe o fator econômico para sua consecução: a racionalidade "técnica" depende das condições materiais disponíveis ao agente para que se efetue.

Fazendo o escrutínio da escrita weberiana, Sell (2011, p. 565-577) observa que o termo "técnica" busca reunir sob o mesmo jugo os meios e os fins, no sentido de obter a melhor eficácia: os objetivos dimensionarão as técnicas e recursos a serem empregados para o sucesso da ação. Mas são os meios que consubstanciam a "técnica" na medida que são desenhados de acordo com objetivos e possibilidades - aqui reside o cerne da questão visto que o espectro histórico e cultural precisa viabilizar uma "técnica" para que essa ganhe concretude. Em suma, a prática depende não só das "técnicas" disponíveis, mas também do ambiente cultural no qual ela se inscreve.

Há de se lembrar que na ótica weberiana, a análise sociológica toma como referência o sentido que os atores atribuem aos seus atos no contexto social, de modo que para além da "tecnicidade" enquanto operações no plano do modo de produção material, Max Weber coloca em evidência o papel das mentalidades para a formação de um conjunto de práticas, seja no âmbito jurídico, familiar, econômico, etc. Neste sentido podemos identificar o modo de agir social com o modo de agir técnico e assim torna-se evidente que toda ação social possui uma instrumentalidade intrínseca.

O processo de racionalização nutre-se da substituição dos costumes arraigados pela projeção da ação com base em interesses, que podem ser privados ou coletivos. Assim a racionalização implica numa colonização do mundo da vida pela instrumentalidade e a tecnicidade de modo que a secularização e desencanto do mundo levam a uma forma de vida calcada na racionalização técnica.

\footnotetext{
${ }^{3}$ Sobre o tema vide "NIETZSCHE, Friedrich. Humano Demasiado Humano (tradução de Paulo Cezar de Souza). São Paulo: Companhia das Letras, 2000".
} 
Dito isso, Sell (2011, p. 580-581) chega ao veredito de que a prevalência da burocracia sobre o carisma significa que os meios passaram a subjugar os fins, desviando as instituições de sua atividade-fim para outra afeita ao seu aparato burocrático. Se por um lado há um avanço no sentido de despersonalizar as relações de poder, por outro lado, isso implicaria numa crescente petrificação do modus operandi de instituições públicas, empresas, partidos, igrejas, etc. Assim as práticas administrativas na sociedade moderna levariam a uma irrefutável desumanização das organizações pela imposição de rotinas impessoais e rígidas.

\section{CÓDIGO PENAL E A CONDIÇÃO PRISIONAL}

Na visão de Silveira (2006, p. 172-173) Max Weber distinguirá o campo do direito como relativo ao dever ser enquanto o campo da sociologia relativo à realidade efetiva das coisas. Assim o direito se preocupa com as normas e sua lógica interna enquanto ordenamento jurídico. A sociologia por sua vez se debruça sobre a efetividade e legitimidade das leis ante a estrutura e dinâmica sociais.

É preciso estabelecer uma distinção entre a dogmática jurídica e a sociológica jurídica. A primeira procura estabelecer teoricamente o sentido intrínseco visado por uma lei, controlar-lhe a coerência lógica em relação a outras leis, ou mesmo em relação ao conjunto de um código. A sociologia jurídica, ao invés, tem por objeto compreender o comportamento significativo dos membros de um grupamento quanto às leis em vigor e determinar o sentido da crença em sua validade ou na ordem que elas estabeleceram. Procura, pois, apreender até que ponto as regras de direito são observadas, e como os indivíduos orientam de acordo com elas a sua conduta. Para a dogmática jurídica uma norma é válida desde que seja estabelecida ou figure em um código; para a sociologia trata-se de controlar sua importância no curso da atividade social dos indivíduos, pois não é sempre que uma lei estabelecida é respeitada (FREUND, 2006, p. 178-179).

Na lógica do sistema penal a privação de liberdade além de criar a sensação de segurança junto à opinião pública também permite um saber clínico acerca dos infratores visto que estão sob permanente vigilância. Um contraste emerge de saída: a lei exige a individualização da pena, mas seu cumprimento numa instituição total retira qualquer possibilidade de tratamento clínico da questão visto que o detento integrará uma massa amorfa de presidiários. Caberá ao interno criar por si mesmo as táticas de sobrevivência e descolamento dessa massa de proscritos. Na ótica do detento a pena prevista é tão 
somente uma projeção, visto que será a sua trajetória e o comportamento intramuros no cárcere que determinará o prazo provável de permanência.

A partir do momento que o sujeito ingressa no sistema prisional toma curso um processo de alienação do mesmo em dois sentidos: em direção ao mundo externo do qual ele deixa de ser membro da sociedade civil e em direção ao mundo interno à prisão no qual ele passa a pertencer à instituição e fica submetido à lógica de força e poder das relações internas. Disso decorre, como expõe Fonseca (2006, p. 534-535), a mortificação do sujeito em nome da disciplina e da ordem. A ideia básica da proposta de reabilitação penal consiste em transmutar sujeitos inseridos em práticas criminais em cidadãos ativos, mas a exclusão operada pelo sistema prisional de modo substantivo vai no curso oposto do que se propõe formalmente.

Ainda segundo mesmo autor, os problemas carcerários na realidade brasileira podem ser divisados em dois grupos: de um lado situam-se as mazelas de ordem estrutural como a falta de equipe administrativa e segurança; por outro lado os problemas da natureza da privação de liberdade que isola o sujeito da família e sociedade, fazendo-o submergir no mundo do crime do qual a carceragem é constituída.

Em termos de segurança pública, de acordo com Cardoso e Monteiro (2013, p. 9599) o debate é travado entre duas vertentes: a primeira, repressiva, entende que as medidas de combate ao criminoso devem ser a tônica da ação estatal, implicando na expansão do aparato policial, da máquina judicial e prisional; a segunda, preventiva, destaca o combate ao crime através de ações voltadas para o cidadão comum com a inclusão social, redução da desigualdade e promoção dos direitos humanos.

Nessa perspectiva os mesmos autores entendem que os governos no contexto do neoliberalismo têm procurado tratar da questão de segurança pública com base na ótica da repressão. As consequências dessa escolha foram a expansão das vagas no sistema prisional, ainda que em número insuficiente visto a expansão também da detenção de pessoas e do processo de privação de liberdade ${ }^{4}$. Constata-se que nas delegacias e cadeias se avolumam presos em detenção provisória ou transitada em julgado à revelia do que

\footnotetext{
${ }^{4}$ Parafraseando a célebre tese de Thomas Malthus sobre estudos populacionais, podemos dizer que as vagas em instituições penais crescem em termos aritméticos enquanto a demanda do sistema judiciário por encarceramento cresce de forma geométrica.
} 
prevê a legislação. A permanência de detentos acima do prazo legal em instituições desprovidas de amparo legal e estrutural para a guarda dos mesmos constitui prática que atenta contra os direitos humanos fundamentais.

Para fins de análise do objeto de tela é mister divisar algumas noções acerca do que prevê nosso ordenamento penal no que tange às regras para encarceramento. Do ponto de vista formal podemos elencar algumas modalidades de prisão peremptória com previsão em lei:

Quadro 1 - Síntese das modalidades de prisão

\begin{tabular}{|c|c|c|}
\hline Tipo & Fundamento legal básico & Súmula \\
\hline Prisão em flagrante & $\begin{array}{l}\text { Capitulo II do Código de } \\
\text { Processo Penal, modificado } \\
\text { pela Lei no } 12.403 \text {, de } 2011 .\end{array}$ & Quando ocorre na presença de flagrante delito. \\
\hline Prisão preventiva & $\begin{array}{l}\text { Capitulo III do Código de } \\
\text { Processo Penal, modificado } \\
\text { pela Lei } n=12.403 \text {, de } 2011 .\end{array}$ & $\begin{array}{l}\text { Pode ser decretada pelo juiz em qualquer fase do } \\
\text { inquérito ou da instrução criminal, para garantir a } \\
\text { ordem jurídica e social, exigindo-se a } \\
\text { demonstração do fumus boni juiris e do periculum } \\
\text { in mora. }\end{array}$ \\
\hline $\begin{array}{l}\text { Prisão } \\
\text { administrativa }\end{array}$ & $\begin{array}{l}\text { O art. 50, LXI, da CF e os arts. } \\
319 \text { e } 320 \text { do Código de } \\
\text { Processo Penal. Foi } \\
\text { explicitamente revogada } \\
\text { pela Lei } n=12.403 \text {, de } 2011 .\end{array}$ & $\begin{array}{l}\text { Versa sobre os remissos ou omissos em entrar para } \\
\text { os cofres públicos com dinheiro a seu cargo, para } \\
\text { compeli-los a que o façam. A prisão administrativa } \\
\text { somente poderia ser determinada pelo juiz } \\
\text { competente. }\end{array}$ \\
\hline $\begin{array}{l}\text { Prisão por } \\
\text { pronúncia }\end{array}$ & $\begin{array}{l}\text { O art. } 373 \text { o do Código de } \\
\text { Processo Penal, Decreto-lei } \\
\text { no } 3.689 \text {, de } 3 \text { de outubro de } \\
1941 .\end{array}$ & $\begin{array}{l}\text { A prisão por pronúncia deriva de sentença da } \\
\text { mesma natureza, para os casos de competência do } \\
\text { tribunal do júri nos crimes dolosos contra a vida. }\end{array}$ \\
\hline $\begin{array}{l}\text { Prisão resultante } \\
\text { de sentença } \\
\text { condenatória } \\
\text { recorrível }\end{array}$ & $\begin{array}{l}\text { O art. } 373 \text { o do Código de } \\
\text { Processo Penal, Decreto-lei } \\
\text { no } 3.689 \text {, de } 3 \text { de outubro de } \\
1941 .\end{array}$ & $\begin{array}{l}\text { Resultante de sentença penal condenatória } \\
\text { recorrível, ou seja, situação que ainda não } \\
\text { transitou em julgado mas na qual se considerou o } \\
\text { réu culpado e indicando ao mesmo pena privativa } \\
\text { de liberdade. }\end{array}$ \\
\hline Prisão temporária & $\begin{array}{l}\text { O art. } 283^{\circ} \text { do Código de } \\
\text { Processo Penal, Decreto-lei } \\
\text { no } 3.689 \text {, de } 3 \text { de outubro de } \\
\text { 1941, modificado pela Lei no } \\
\text { 12.403, de } 2011 \text {. }\end{array}$ & $\begin{array}{l}\text { Resultante de ordem escrita e fundamentada da } \\
\text { autoridade judiciária competente no curso da } \\
\text { investigação ou do processo. }\end{array}$ \\
\hline
\end{tabular}

Fonte: Código de Processo Penal (1941/2011). Compilação do autor.

De igual modo podemos elencar os vários tipos de flagrantes ${ }^{5}$ que implicam em detenção.

\footnotetext{
${ }^{5}$ Resta observar que no ordenamento jurídico nacional não se permite o flagrante previamente elaborado para fins de prisão, conforme disciplina a Súmula 146 do Supremo Tribunal Federal, que versa sobre a prescrição da pretensão punitiva, na modalidade retroativa, após o advento da Lei 12.234/2010.
} 
Quadro 2 - Tipos de prisão em flagrante

\begin{tabular}{|l|l|}
\hline Tipos de flagrante & Características \\
\hline Flagrante próprio & $\begin{array}{l}\text { Aquele no qual o agente é detido cometendo o crime ou imediatamente após } \\
\text { praticá-lo. }\end{array}$ \\
\hline Flagrante impróprio & $\begin{array}{l}\text { Aquele no qual o agente é perseguido logo após o ilícito havendo presunção de } \\
\text { culpa. }\end{array}$ \\
\hline Flagrante presumido & $\begin{array}{l}\text { Aquele no qual o agente é detido logo após a ocorrência criminal em posse de } \\
\text { instrumentos, armas, objetos ou papéis que permitam presumir ser ele o } \\
\text { infrator. }\end{array}$ \\
\hline Infração permanente & $\begin{array}{l}\text { Exemplo típico dessa modalidade é o caso de sequestro, quando há uma } \\
\text { continuidade temporal da ação criminal, nesse caso sendo o agente considerado } \\
\text { em flagrante delito enquanto durar a ação. }\end{array}$ \\
\hline Flagrante esperado & $\begin{array}{l}\text { Aquele no qual a força policial em posse de informação sobre delito em curso age } \\
\text { no sentido de deter o infrator e realizar a prisão. }\end{array}$ \\
\hline
\end{tabular}

Fonte: Código de Processo Penal (1941/2011). Compilação do autor.

Indica de forma acertada Soares (2014, p. 80-81) que um dos problemas lógicos da prisão provisória junto ao ordenamento jurídico é que a mesma conflita com o princípio constitucional da presunção de inocência, visto que esse instituto legal fundamental prevê que nenhum cidadão pode ser considerado culpado até que transcorra o transitado em julgado e tome forma a sentença penal de condenação. Doutra sorte o que temos com a prisão provisória é a antecipação da pena à revelia do processo penal. O que se deseja deixar claro aqui é que, assim como o próprio nome sugere, a prisão provisória não decorre de condenação com trânsito em julgado, diante do que não pode ser definitiva, tendo em vista a presunção de inocência e o devido processo legal que presidem a apuração e o julgamento do acusado. Muitas vezes, só ao final do julgamento, na instância superior, consegue-se provar a inocência daquele que foi acusado indevidamente ou por equívoco. No caso em que se coloque em prática a prisão provisória e no decurso do processo transitado em julgado restar firmada a inocência do réu ficará caracterizado um dano irreparável ao mesmo. Daí o caráter excepcional que deve ter toda forma de prisão provisória.

A prisão preventiva, por sua vez, é passível de aplicação mesmo durante a investigação criminal, cabendo aos casos previstos no capítulo III do Código de Processo Penal, Decreto-lei no 3.689, de 3 de outubro de 1941, modificado pela Lei no 12.403, de 2011: prisão preventiva decretada pelo juiz, de ofício, se no curso da ação penal, ou a 
requerimento do Ministério Público, do querelante ou do assistente, ou por representação da autoridade policial. (NR)

Art. 312. A prisão preventiva poderá ser decretada como garantia da ordem pública, da ordem econômica, por conveniência da instrução criminal, ou para assegurar a aplicação da lei penal, quando houver prova da existência do crime e indício suficiente de autoria.

Parágrafo único. A prisão preventiva também poderá ser decretada em caso de descumprimento de qualquer das obrigações impostas por força de outras medidas cautelares (art. 282, $\S 4^{\circ}$ ). (NR)

Art. 313. Nos termos do art. 312 deste Código, será admitida a decretação da prisão preventiva:

I - nos crimes dolosos punidos com pena privativa de liberdade máxima superior a 4 (quatro) anos;

II - se tiver sido condenado por outro crime doloso, em sentença transitada em julgado, ressalvado o disposto no inciso I do caput do art. 64 do Decreto-Lei $\mathrm{n}^{\circ}$ 2.848, de 7 de dezembro de 1940 - Código Penal;

III - se o crime envolver violência doméstica e familiar contra a mulher, criança, adolescente, idoso, enfermo ou pessoa com deficiência, para garantir a execução das medidas protetivas de urgência;

IV - (revogado).

Parágrafo único. Também será admitida a prisão preventiva quando houver dúvida sobre a identidade civil da pessoa ou quando esta não fornecer elementos suficientes para esclarecê-la, devendo o preso ser colocado imediatamente em liberdade após a identificação, salvo se outra hipótese recomendar a manutenção da medida. (NR)

Art. 314. A prisão preventiva em nenhum caso será decretada se o juiz verificar pelas provas constantes dos autos ter o agente praticado o fato nas condições previstas nos incisos I, II e III do caput do art. 23 do Decreto-Lei ${ }^{\circ} 2.848$, de 7 de dezembro de 1940 - Código Penal. (NR)

Art. 315. A decisão que decretar, substituir ou denegar a prisão preventiva será sempre motivada (NR).

Lembra Soares (2014, p. 84-87) que a legislação veda a prisão preventiva em casos de crime famélico, legitima defesa e cumprimento da lei ou exercício do direito vigente. Doutra sorte pode ser evocada como forma de garantir a ordem pública e econômica, para fins de instrução criminal, aplicação da lei na evidencia de autoria de crime bem como nos casos de ruptura com medidas cautelares previamente impostas. Veja-se que aqui se tratam de situações excepcionais. Na prática comum a prisão preventiva é passível de admissibilidade em presença de crimes dolosos nos quais se tem a previsão de pena restritiva de liberdade. Criminosos reincidentes também são passíveis de submissão ao regime de prisão preventiva.

Sobre a prisão temporária o art. 10 da Lei no $7.960 / 89$ dispõe dos casos nos quais ela é cabível: 
Art. $1^{\circ}$ Caberá prisão temporária: I - quando imprescindível para as investigações do inquérito policial; II - quando o indicado não tiver residência fixa ou não fornecer elementos necessários ao esclarecimento de sua identidade; III - quando houver fundadas razões, de acordo com qualquer prova admitida na legislação penal, de autoria ou participação do indiciado nos seguintes crimes: a) homicídio doloso (art. 121, caput, e seu $\S 2^{\circ}$ ); b) seqüestro ou cárcere privado (art. 148 , caput, e seus $\S \S 1^{\circ}$ e $2^{\circ}$ ); c) roubo (art. 157 , caput, e seus $\S \S 1^{\circ}, 2^{\circ}$ e $3^{\circ}$ ); d) extorsão (art. 158, caput, e seus $\S \S 1^{\circ}$ e $2^{\circ}$ ); e) extorsão mediante seqüestro (art. 159 , caput, e seus $\S \S 1^{\circ}, 2^{\circ}$ e $3^{\circ}$ ); f) estupro (art. 213, caput, e sua combinação com o art. 223, caput, e parágrafo único); g) atentado violento ao pudor (art. 214, caput, e sua combinação com o art. 223, caput, e parágrafo único); h) rapto violento (art. 219, e sua combinação com o art. 223 caput, e parágrafo único); i) epidemia com resultado de morte (art. $267, \S 1^{\circ}$ ); j) envenenamento de água potável ou substância alimentícia ou medicinal qualificado pela morte (art. 270, caput, combinado com art. 285); I) quadrilha ou bando (art. 288), todos do Código Penal; $\mathrm{m}$ ) genocídio (arts. $1^{\circ}, 2^{\circ}$ e $3^{\circ}$ da Lei $n^{\circ} 2.889$, de $1^{\circ}$ de outubro de 1956 ), em qualquer de sua formas típicas; $n$ ) tráfico de drogas (art. 12 da Lei $n^{\circ} 6.368$, de 21 de outubro de 1976); o) crimes contra o sistema financeiro (Lei $n^{\circ} 7.492$, de 16 de junho de 1986). p) crimes previstos na Lei de Terrorismo (incluído pela Lei $n$ o $\underline{13.260 \text {, de 2016). }}$.

Conforme prevê o diploma legal a prisão temporária tem como escopo a cautela prévia ao julgamento e à aplicação da pena. Não está no seu horizonte a aplicação efetiva da pena nem tampouco sua antecipação, seja à revelia do transitado em julgado ou após este, caso no qual havendo condenação privativa de liberdade, o réu deverá ser encaminhado à unidade prisional.

A intenção da lei em todos esses tipos de prisão até aqui descritos é resguardar a aplicação correta do que se prevê no código penal e evitar a elisão do jus puniendi por ocasião de impunidade, como no caso de fuga do réu, eliminação de provas e coação de testemunhas, situações que poderiam comprometer as investigações criminais e a aplicação da lei.

Nesse sentido não é permitido pelo ordenamento jurídico o emprego da prisão provisória para atender ao clamor da opinião pública em casos de grande repercussão midiática, visto que, sem o devido transitado em julgado e sem esgotar as investigações e recolhimento de provas nada se pode afirmar em definitivo sem incorrer no risco de imputar crime a inocente. Pelo exposto, resta evidente que a prisão provisória deverá sempre ser precedida da correta aplicação do princípio da presunção de inocência.

Até aqui tratamos daquilo que se prevê na letra da lei. Mas como ensina Max Weber é papel da sociologia contrapor as ideias aos fatos. Nesse caso, se partirmos do 
reconhecimento de que as prisões são instituições totalitárias no sentido de sua intencionalidade de disciplinar corpo e mente pelo emprego da repressão fica esclarecido que sua capacidade regenerativa é bastante diminuta a partir do momento em que em nada se assemelha ao modus operandi de uma sociedade democrática. Nada é consentido, tudo é imposto. O Estado de direito através do sistema penal proscreve parcela significativa da população a um regime de exceção.

Observa Vigna (2015, p. 1) em outra dimensão, mais operacional e prática, que a própria inviabilidade de efetivação do ordenamento jurídico pode ensejar por parte dos operadores do sistema penal a desobediência calculada tendo em vista sua percepção de que por necessidade de sobrevivência ou para controlar a vida intramuros.

Noutro ponto há de se destacar de acordo com Matsuda (2015, p. 4) que temas recorrentes na pauta do poder legislativo como a redução da maioridade penal e a ampliação nos gastos com vigilância e construção de unidades prisionais evidenciam a limitação da visão sobre a segurança pública, em geral abarcada pela perspectiva repressiva.

De acordo com os dados do Departamento Penitenciário Nacional (DEPEN) nossa população carcerária indica uma grave seletividade no aprisionamento de pessoas, visto que em geral os detentos são jovens, negros, com baixa escolaridade. Os principais indicadores para o período 2011/2014 estão sumarizados nos quadros a seguir e servem de amostra do que dizemos aqui.

Quadro 3 - Escolaridade da população carcerária

\begin{tabular}{|l|l|l|l|}
\hline Quantidade de presos por grau de instrução & $\mathbf{2 0 1 1}$ & $\mathbf{2 0 1 4}$ & Variação \\
\hline Analfabeto & 26.410 & 19.487 & $-26,21 \%$ \\
\hline Alfabetizado & 58.380 & 32.880 & $-43,67 \%$ \\
\hline Ensino Fundamental Incompleto & 216.660 & 242.222 & $11,79 \%$ \\
\hline Ensino Fundamental Completo & 59.046 & 72.216 & $20,67 \%$ \\
\hline Ensino Médio Incompleto & 52.843 & 68.192 & $29,04 \%$ \\
\hline Ensino Médio Completo & 36.289 & 46.602 & $28,41 \%$ \\
\hline Ensino Superior Incompleto & 3.757 & 4.623 & $23,05 \%$ \\
\hline Ensino Superior Completo & 1.906 & 2.253 & $18,20 \%$ \\
\hline Ensino acima de Superior Completo & 152 & 107 & $-29,60 \%$ \\
\hline
\end{tabular}

Fonte: Infopen, 2011, 2014. Compilação do autor. 
Quadro 4 - Faixa etária da população carcerária

\begin{tabular}{|l|l|l|l|}
\hline Quantidade de presos por faixa etária & $\mathbf{2 0 1 1}$ & $\mathbf{2 0 1 4}$ & Variação \\
\hline 18 a 24 anos & 134.255 & 158.185 & $17,82 \%$ \\
\hline 25 a 29 anos & 117.602 & 131.119 & $11,49 \%$ \\
\hline 30 a 34 anos & 84.905 & 99.487 & $17,17 \%$ \\
\hline 35 a 45 anos & 76.516 & 95.600 & $24,94 \%$ \\
\hline 46 a 60 anos & 28.752 & 35.453 & $23,30 \%$ \\
\hline mais de 60 anos & 4.849 & 5.640 & $16,31 \%$ \\
\hline
\end{tabular}

Fonte: Infopen, 2011, 2014. Compilação do autor.

Quadro 5 - Perfil étnico racial da população carcerária

\begin{tabular}{|l|l|l|l|}
\hline Quantidade de presos por cor de pele/etnia & $\mathbf{2 0 1 1}$ & $\mathbf{2 0 1 4}$ & Variação \\
\hline Branca & 166.340 & 188.695 & $13,43 \%$ \\
\hline Negra & 75.883 & 91.057 & $19,99 \%$ \\
\hline Parda & 198.175 & 221.568 & $11,80 \%$ \\
\hline Amarela & 2.180 & 3.312 & $51,92 \%$ \\
\hline Indígena & 769 & 666 & $-13,39 \%$ \\
\hline Outras & 10.809 & 1.608 & $-85,12 \%$ \\
\hline
\end{tabular}

Fonte: Infopen, 2011, 2014. Compilação do autor.

Tanto entre homens quanto mulheres destaca-se a expansão de detenção por crimes relativos ao tráfico de drogas, embora nesse quesito a parcela feminina seja proporcionalmente maior. Até nisso o sistema é discriminatório visto que o universo do tráfico é um microcosmo que em muito reproduz a sociedade em geral, sendo marcado pelo machismo e a exploração das mulheres. Os chefes de tráfico comumente são pessoas do sexo masculino que empregam mulheres como meio de transporte e distribuição de cargas ilícitas. Estas últimas são mais suscetíveis de aprisionamento visto que operam na ponta comercial do sistema e não na ponta de gestão.

Quadro 6 - Tipos de crimes mais comuns

\begin{tabular}{|l|l|l|l|}
\hline Criminalidade & $\mathbf{2 0 1 1}$ & $\mathbf{2 0 1 4}$ & Variação \\
\hline Quantidade de crimes tentados/consumados & 493.275 & 353.181 & $-28,40 \%$ \\
\hline Crimes contra a pessoa & 60.567 & 68.982 & $13,89 \%$ \\
\hline Crimes contra o patrimônio & 240.848 & 244.114 & $1,36 \%$ \\
\hline Entorpecentes & 125.560 & 147.475 & $17,45 \%$ \\
\hline
\end{tabular}

Fonte: Infopen, 2011, 2014. Compilação do autor.

De acordo com o diagnóstico de Matsuda (2015, p. 6) a chamada lei de drogas (Lei 11.343/2006) ao vedar o emprego da pena privativa de liberdade para usuários de drogas prevendo o tratamento e não o encarceramento nesses casos (em tese um avanço) levou 
ao efeito colateral do acirramento da repressão ao comércio de drogas como ferramenta de combate ao uso de entorpecentes (na prática um retrocesso). A população carcerária aumenta em meio a condições precárias de instalação física dos estabelecimentos penais e parcos recursos para manutenção de pessoal e serviços de educação, assistência social e saúde. Não raro as famílias dos detentos precisam dar suporte com itens básicos que de acordo com a Lei de Execução Penal deveriam ser fornecidos pelo poder público, como no caso de alimentos e higiene. Em vista da ausência de assistência proliferam os grupos de crime organizado como gerentes paralelos do sistema penal.

Um dos fatores que podem ser elencados para o agravamento na superlotação dos presídios reside na prática da privação de liberdade de pessoas cujo processo ainda não transitou em julgado, de modo que o provisório se transforma em permanente e acirra o aspecto degradante do sistema prisional. Sem a necessidade de sentença judicial, a prisão antes ou durante o processo criminal deveria ser caso excepcional, mas no contexto do Estado penal e da penalização da pobreza ela se torna a norma.

De fato, pela previsão legal, a prisão provisória e congêneres aqui descritos deveriam ser empregados na defesa e proteção da pessoa acusada, tendo em vista risco vital a esta infligida, mas o que transcorre é o posto, sendo essa aplicada como antecipação de pena presumida. Para Tavares e Menandro (2004, p. 86-87) o sistema prisional reforça a exclusão social em vez de combatê-la. A precariedade socioeconômica de parcela significativa da população encontra seu eco na precariedade de nossas instituições penais.

Tornar visível a criminalidade pela ação midiática e a seguir pela ação do aparato policial tornar invisível o sujeito do crime na condição de apenado é uma estratégia de manutenção de um sistema excludente: "tirar de circulação um meliante" é o correspondente social a uma operação cirúrgica no campo da medicina e uma ação de "limpeza social", como se fosse possível "varrer a criminalidade da cidade" por meio da repressão. Cria-se um círculo vicioso no qual o grupo social em condição de vulnerabilidade se por ventura incorrer em infrações legais irá encontrar a repressão e coação no internato penal. Caso consiga cumprir sua pena privativa de liberdade e retornar à sociedade as condições de exclusão que o levaram ao crime e ao cárcere terão 
se agravado pelo estigma da sua passagem pelo sistema prisional. Em nenhum momento se questiona as condições de vulnerabilidade a que o grupo está sujeito e, portanto, o mesmo não será alvo de políticas sociais, restando a este a face repressiva do Estado. Os quadros seguintes sintetizam as informações disponíveis para os casos de prisões provisórias no Brasil para o ano de 2014 segundo dados do Departamento Penitenciário Nacional - DEPEN por região:

Quadro 7 - Síntese das prisões provisórias no Brasil - Região Norte

\begin{tabular}{|c|c|c|c|c|c|c|c|c|}
\hline 岂 & 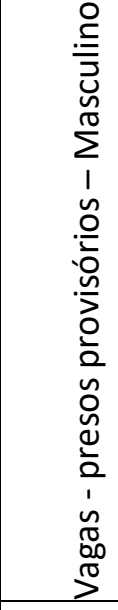 & 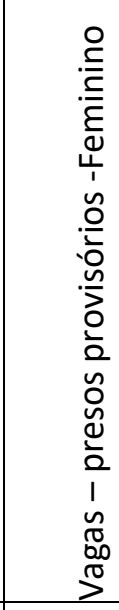 & 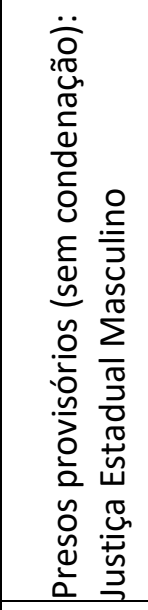 & 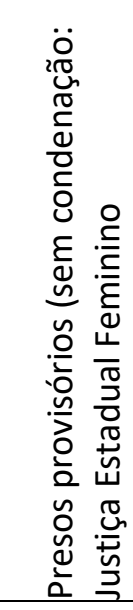 & 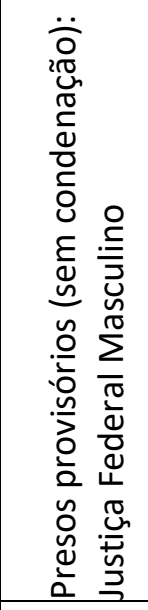 & 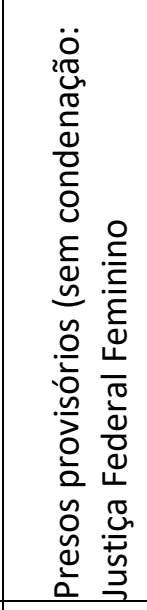 & 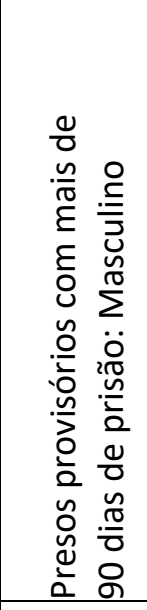 & 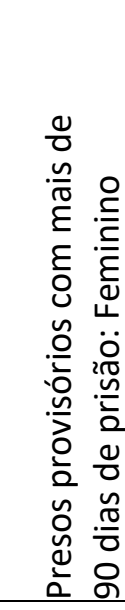 \\
\hline$A C$ & 362 & 5 & 600 & 71 & 0 & 0 & 285 & 0 \\
\hline AM & 2163 & 202 & 3780 & 292 & 90 & 17 & 1233 & 174 \\
\hline AP & 706 & 47 & 674 & 39 & 3 & 0 & 392 & 0 \\
\hline PA & 3057 & 255 & 5333 & 425 & 21 & 4 & 1401 & 2 \\
\hline RO & 1047 & 148 & 1156 & 58 & 31 & 0 & 221 & 1 \\
\hline $\mathrm{RR}$ & 24 & 36 & 772 & 33 & 0 & 2 & 17 & 0 \\
\hline TO & 943 & 88 & 1368 & 52 & 15 & 1 & 117 & 32 \\
\hline
\end{tabular}

Fonte: Infopen (2014). Compilação do autor. 
Quadro 8 - Síntese das prisões provisórias no Brasil - Região Nordeste

\begin{tabular}{|c|c|c|c|c|c|c|c|c|}
\hline 岇 & 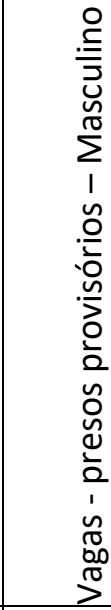 & 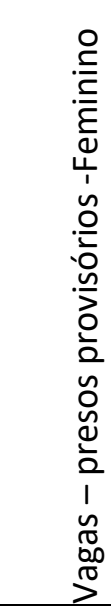 & 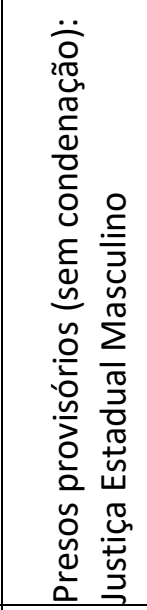 & 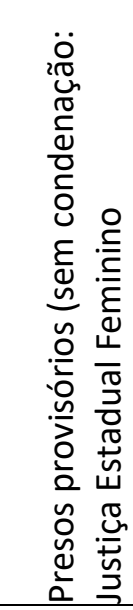 & 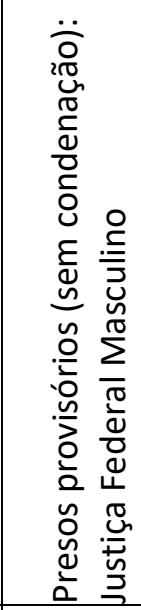 & 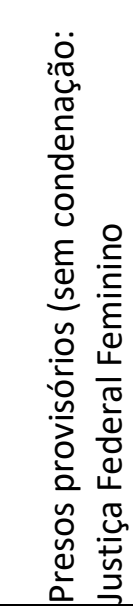 & 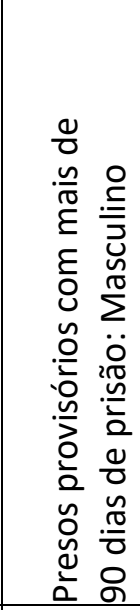 & 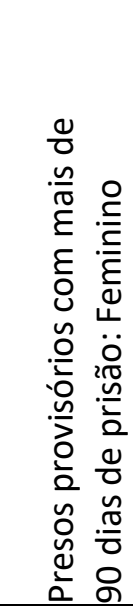 \\
\hline $\mathrm{AL}$ & 630 & 0 & 1893 & 186 & 0 & 0 & 38 & 2 \\
\hline BA & 1184 & 0 & 6064 & 383 & 40 & 5 & 1302 & 148 \\
\hline CE & 8161 & 178 & 9348 & 238 & 0 & 0 & 8807 & 235 \\
\hline MA & 2097 & 129 & 2306 & 121 & 0 & 0 & 301 & 3 \\
\hline PB & 1850 & 76 & 3195 & 220 & 152 & 4 & 611 & 17 \\
\hline PE & 4731 & 223 & 17528 & 1036 & 48 & 0 & 3061 & 116 \\
\hline $\mathrm{PI}$ & 244 & 103 & 1915 & 116 & 16 & 2 & 29 & 26 \\
\hline RN & 1641 & 100 & 2120 & 160 & 43 & 0 & 490 & 65 \\
\hline SE & 1678 & 8 & 2625 & 251 & 0 & 0 & 895 & 0 \\
\hline
\end{tabular}

Fonte: Infopen (2014). Compilação do autor.

Quadro 9 - Síntese das prisões provisórias no Brasil - Região Centro-Oeste

\begin{tabular}{|c|c|c|c|c|c|c|c|c|}
\hline 岂 & 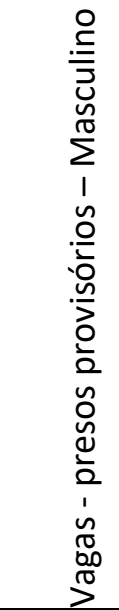 & 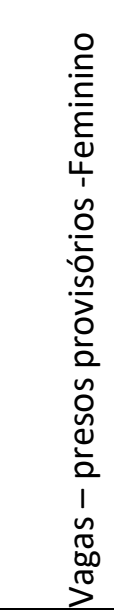 & 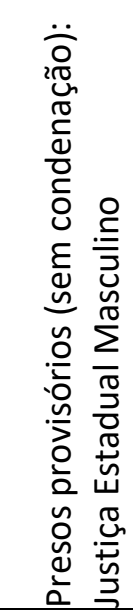 & 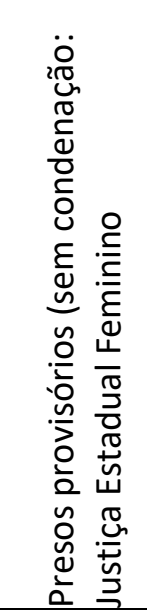 & 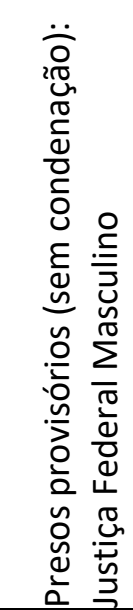 & 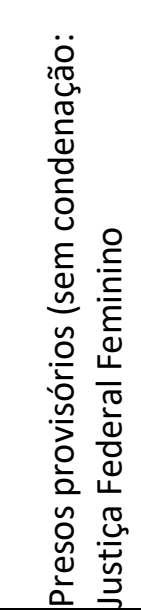 & 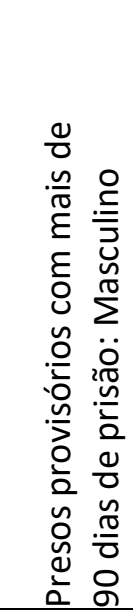 & 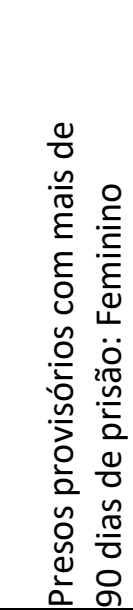 \\
\hline $\mathrm{DF}$ & 1050 & 84 & 3462 & 185 & 13 & 10 & 9 & 20 \\
\hline GO & 2815 & 268 & 5973 & 406 & 14 & 3 & 183 & 6 \\
\hline MS & 336 & 0 & 2888 & 418 & 221 & 56 & 553 & 213 \\
\hline MT & 3693 & 309 & 4979 & 235 & 244 & 4 & 2220 & 33 \\
\hline
\end{tabular}

Fonte: Infopen (2014). Compilação do autor. 
Quadro 10 - Síntese das prisões provisórias no Brasil - Região Sudeste

\begin{tabular}{|c|c|c|c|c|c|c|c|c|}
\hline 岂 & 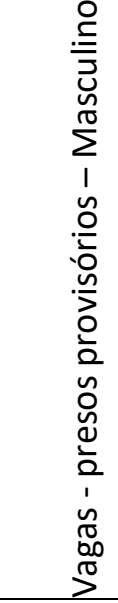 & 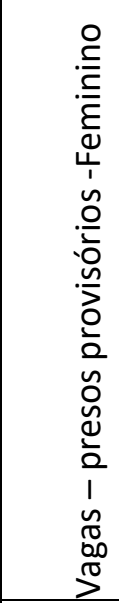 & 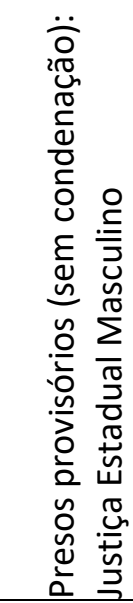 & 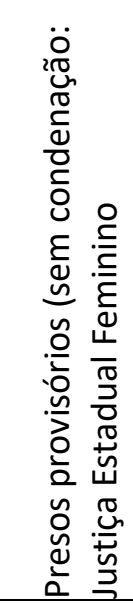 & 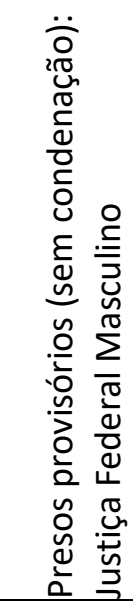 & 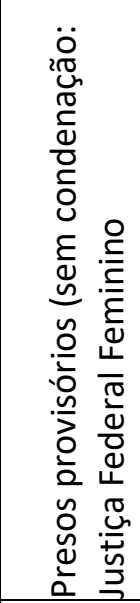 & 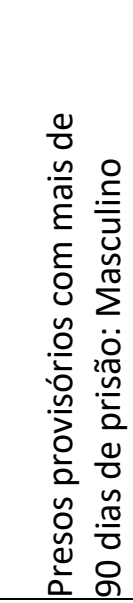 & 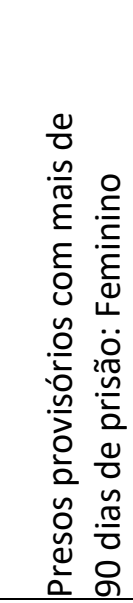 \\
\hline ES & 5341 & 419 & 6640 & 544 & 0 & 5 & 3397 & 278 \\
\hline MG & 12582 & 1056 & 25494 & 1780 & 92 & 2 & 2651 & 155 \\
\hline RJ & 8517 & 273 & 16741 & 512 & 8 & 770 & 247 & 0 \\
\hline SP & 31972 & 1370 & 64716 & 1364 & 33 & 0 & N/I & $N / I$ \\
\hline
\end{tabular}

Fonte: Infopen (2014). Compilação do autor.

Quadro 11 - Síntese das prisões provisórias no Brasil - Região Sul

\begin{tabular}{|c|c|c|c|c|c|c|c|c|}
\hline 岇 & 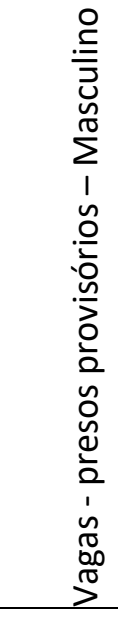 & 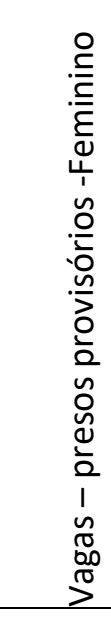 & 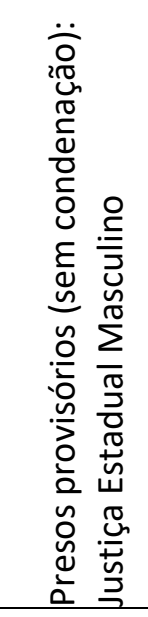 & 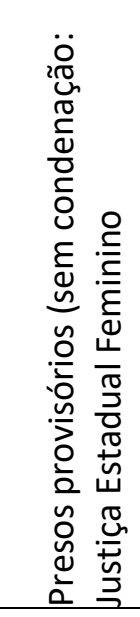 & 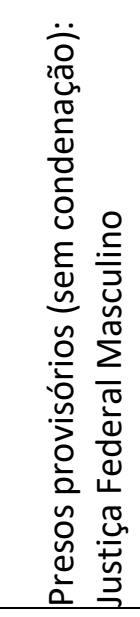 & 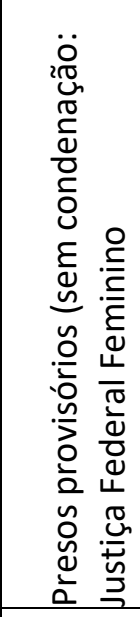 & 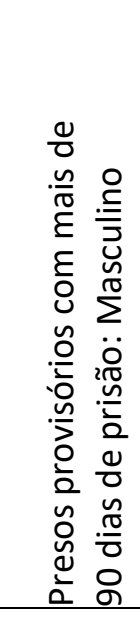 & 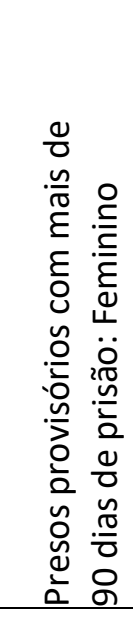 \\
\hline PR & 3592 & 164 & 4414 & 328 & 191 & 44 & 541 & 49 \\
\hline RS & 3359 & 268 & 9197 & 545 & 23 & 4 & 866 & 55 \\
\hline SC & 5614 & 618 & 4161 & 333 & 18 & 2 & 676 & 75 \\
\hline
\end{tabular}

Fonte: Infopen (2014). Compilação do autor.

Vamos analisar de forma descritiva os dados apresentados. No quesito capacidade do estabelecimento em número de vagas para presos provisórios na região Nordeste destacam-se Ceará e Pernambuco na oferta de vagas para o público masculino. Por outro lado, em alguns Estados como Alagoas e Bahia não há registro de vagas para mulheres e no Sergipe são ínfimas. Na região Norte o Pará detém a maior parte das vagas destinadas a 
homens, enquanto no Acre há registro de diminutas vagas destinadas às mulheres. Na região Centro-Oeste o Estado de Mato Grosso lidera o número de vagas para presos provisórios do sexo masculino enquanto no vizinho Mato Grosso do Sul não há registro de vagas desse tipo para mulheres. Na região Sudeste o Estado de São Paulo sozinho tem mais vagas disponíveis para homens do que todos os outros três Estados juntos, liderando também a oferta de vagas para mulheres. Por fim, na região Sul contrariando a expectativa por ser demograficamente o menor é o Estado de Santa Catarina que lidera a oferta de vagas provisórias tanto para homens quanto para mulheres.

No que diz respeito à população prisional provisória na esfera da Justiça Estadual, as estatísticas indicam que na região Nordeste, Pernambuco lidera a oferta de vagas muito à frente dos demais Estados tanto para homens quanto mulheres. Na Região Norte as redes estaduais do sistema prisional têm destaque para o Estado do Pará, enquanto na Região Centro-Oeste é o Estado de Goiás que lidera a oferta para homens, enquanto Mato Grosso do Sul para mulheres por pequena margem. Na região Sudeste como indica o senso comum o Estado de São Paulo detém mais vagas para homens do que todos os outros Estados, porém é Minas Gerais que oferta mais vagas para mulheres. Por fim, na Região Sul a maior parcela das vagas está no Rio Grande do Sul, tanto para homens, quanto para mulheres.

O quadro a seguir indica a sobretaxa de ocupação em termos de presos provisórios relativos às vagas disponíveis. Observe-se que tanto para homens quanto para mulheres a taxa de ocupação praticamente dobra em vista das vagas disponíveis.

Quadro 12 - Síntese das taxas de ocupação

\begin{tabular}{|l|l|l|l|}
\hline Sexo & Vagas & Presos provisórios & Proporção \\
\hline Masculino & 109523 & 210710 & $192,38 \%$ \\
\hline Feminino & 6427 & 11266 & $175,29 \%$ \\
\hline Total & 115950 & 221976 & $191,44 \%$ \\
\hline
\end{tabular}

Fonte: Infopen (2014). Compilação do autor.

Após descrever em linhas gerais a disponibilidade do sistema prisional no que tange à prisão provisória, podemos passar aos dados centrais da pesquisa, que residem nos casos de presos provisórios com mais de 90 dias de prisão. Convém aqui discernir os prazos máximos previstos para a prisão preventiva. Legalmente a mesma não poderá ultrapassar 
180 dias quando for decretada no decurso da investigação ou antes da sentença condenatória recorrível. Doutra sorte terá como prazo máximo 360 dias se for decretada ou tiver seu efeito prorrogado por ocasião da sentença condenatória recorrível. Em caráter excepcional esses prazos podem ser prorrogados, quando na avaliação do juiz couber, mas nesse caso o mesmo terá por obrigação indicar de saída qual deverá ser o prazo de duração da medida. Estabelece também o ordenamento jurídico que a prisão preventiva que exceder a 90 dias deverá passar por reexame do juiz ou tribunal de competência que pode dar prosseguimento ou não após verificar se há persistência dos motivos causais ou mesmo substituir por medida cautelar diversa. Sendo então esse prazo de 90 dias uma espécie de "módulo penal" será o mesmo utilizado neste estudo como referência para a aplicação do referido instituto da prisão preventiva. O quadro a seguir sintetiza a taxa de detenção provisória por mais de 90 dias. Observe-se que tanto para homens quanto para mulheres a taxa de detenção dessa modalidade acima de 90 dias gira em torno de $15 \%$, ou seja, para cada conjunto de 100 detentos provisórios cerca de 15 estão detidos a mais de 90 dias.

Quadro 13 - Síntese das taxas de prisões provisórias a mais de 90 dias

\begin{tabular}{|l|l|l|l|}
\hline & $\begin{array}{l}\text { Presos } \\
\text { provisórios }\end{array}$ & A mais de 90 dias & Proporção \\
\hline Masculino & 210710 & 30569 & $14,50 \%$ \\
\hline Feminino & 11266 & 1705 & $15,14 \%$ \\
\hline Total & 221976 & 32274 & $14,53 \%$ \\
\hline
\end{tabular}

Fonte: Infopen (2014). Compilação do autor.

Na região Nordeste o Estado do Ceará é o que detém o maior número de homens e mulheres detidos em regime provisório a mais de 3 meses. Piauí e Alagoas possuem baixos indicadores nesse quesito.

Na região Norte o Amapá lidera as estatísticas de presos provisórios com mais de 90 dias de detenção, tanto para homens quanto para mulheres. Por outro lado, Pará, a despeito da proporção demográfica, indica baixos quantitativos no cômputo geral.

$\mathrm{Na}$ região Centro-Oeste o Mato Grosso é o Estado com mais detentos nessa condição de provisoriedade a mais de 90 dias, enquanto o Distrito Federal tem reduzido números para homens e mulheres e Goiás poucos casos para mulheres. 
Na região Sudeste não dispomos de dados sobre o Estado de São Paulo, o que dificulta a comparação a nível região ou nacional. Contudo é digno de nota que o Estado do Rio de Janeiro não apresenta nas estatísticas mulheres na condição de presas provisórias com mais de 90 dias e reduzido número de homens nessa condição quando comparado com Minas Gerais e Espírito Santo, aliás, cabendo registro de que este último, a despeito de ser o menor Estado da região, detém o maior número de casos registrados para homens e mulheres (ressalvado, como mencionado, a falta de dados sobre São Paulo).

Por fim, na região Sul do Brasil, os presos provisórios com mais de 90 dias de detenção têm relativa proporcionalidade entre os Estados, tanto no caso de homens quanto de mulheres. A maior incidência no caso de homens cabe ao Rio Grande do Sul, enquanto para mulheres é Santa Catarina que guarda a maioria.

Em suma verifica-se por todo o país que o instituto da prisão preventiva já se estabeleceu como parte da norma vigente em termos de cultura judicial e vem se transformando em sentença contra o sujeito sobre o qual recai a suspeita de crime a despeito da intencionalidade manifesta da legislação em ser instrumento de defesa e proteção para garantia do curso previsto em no escopo do processo penal.

\section{CONCLUSÃO}

Na perspectiva weberiana vimos que a análise deve contrapor a projeção legal e sua efetivação prática no contexto social. No campo ideal Max Weber destaca que a racionalização do mundo da vida leva à formação das práticas burocráticas impessoais, de tal forma que o funcionário não segue mais seus instintos, mas sim rotinas previamente estabelecidas nas normas e regulamentos que devem ser de conhecimento público. Contudo o mesmo autor nos adverte que o processo de racionalização no campo do direito não encontra correspondência no reconhecimento generalizado da validade das normas e, portanto, também não enseja dos indivíduos atenção às mesmas.

Abre-se então espaço para a vigência de práticas patrimonialistas, nas quais a disciplina das regras formais é substituída pela tradição, pelo privilégio, pelas relações de poder e a "boa vontade" das partes envolvidas. No campo das instituições penais o que se 
percebe é que internamente tanto o quadro administrativo quanto detentos se apropriam da institucionalidade negociando seus interesses conforme a dinâmica de poder. Acima disso paira um Leviatã que meticulosamente gerencia os modos sociais de produção do crime e da criminalidade, conduzindo parcelas significativas da população pobre ao cárcere.

O caso do excesso de emprego de prisões de tipo provisório evidencia que o ordenamento jurídico está sob o jugo do Estado patrimonialista em vez de representar a égide do Estado de Direito. Ao contrário de auferir seu objetivo de proteger o acusado se torna em mecanismo de antecipação de pena à revelia do processo penal em si, levando a uma superlotação do sistema prisional que longe de ser acidental é mesmo o resultado de uma prática elaborada no seio de uma sociedade que prevê ressocialização, mas provê a exclusão social como forma de controle das classes subalternizadas.

\section{REFERÊNCIAS}

BRASIL. Código de Processo Penal, Decreto-lei no 3.689, de 3 de outubro de 1941.

BRASIL. Código de Processo Penal, relativos à prisão processual, fiança, liberdade provisória, demais medidas cautelares, Lei no 12.403, de 2011.

FONSECA, Karina Prates da. (Re)Pensando o crime como uma relação de antagonismo entre seus autores e a sociedade. Psicol. cienc. prof., Brasília, v. 26, n. 4, p. 532-547, dez. 2006.

FREUND, Julien. Sociologia de Max Weber. Rio de Janeiro: Forense Universitária, 2006.

GOHN, Gabriel. Max Weber: Sociologia, 7ạ. Edição, 5ạ. Impressão. São Paulo: Editora Ática, 2003.

MATSUDA, Fernanda Emy. A centralidade da prisão provisória na gestão dos ilegalismos. 39 Encontro Anual da ANPOCS. GT 42 - Violência, criminalidade e punição no Brasil. Caxambu, 2015.

MINISTÉRIO DA JUSTIÇA DO BRASIL. Levantamento Nacional de Informações Penitenciárias - Infopen. Brasília 2011.

MINISTÉRIO DA JUSTIÇA DO BRASIL. Levantamento Nacional de Informações Penitenciárias - Infopen. Brasília 2014. 
MONTEIRO, Felipe Mattos e CARDOSO, Gabriela Ribeiro. A seletividade do sistema prisional brasileiro e o perfil da população carcerária: um debate oportuno. Civitas, Porto Alegre, v. 13, n. 1, p. 93-117, jan./abr. 2013.

RIESEBRODT, Martin. A ética protestante no contexto contemporâneo. Tempo soc., São Paulo, v. 24, n. 1, p. 159-182, 2012.

SELL, Carlos Eduardo. Máquinas petrificadas: Max Weber e a sociologia da técnica..Sci. Stud., São Paulo, v. 9, n. 3, p. 563-583, 2011.

SELL, Carlos Eduardo. Racionalidade e racionalização em Max Weber. Rev. bras. Ci. Soc., São Paulo, v. 27, n. 79, p. 153-172, jun. 2012.

SELL, Carlos Eduardo. Weber no Século XXI: Desafios e Dilemas de um Paradigma Weberiano. Dados, Rio de Janeiro, v. 57, n. 1, p. 35-71, mar. 2014.

SILVEIRA, Daniel Barile da. Max Weber e Hans Kelsen: a sociologia e a dogmática jurídicas. Rev. Sociol. Polit., Curitiba, n. 27, p. 171-179, nov. 2006.

TAVARES, Gilead Marchezi; MENANDRO, Paulo Rogério Meira. Atestado de exclusão com firma reconhecida: o sofrimento do presidiário brasileiro. Psicol. cienc. prof., Brasília, v. 24, n. 2, p. 86-99, jun. 2004.

WEBER, Max. Economia e sociedade: fundamentos da sociologia compreensiva / Max Weber; tradução de Regis Barbosa e Karen Elsabe Barbosa; Revisão técnica de Gabriel Cohn - Brasília, DF: Editora Universidade de Brasília: São Paulo: Imprensa Oficial do Estado de São Paulo, 1999.

VIGNA, Ana. Burocracia atrás das grades: a aplicação da norma no sistema prisional. IV ENADIR - Encontro Nacional de Antropologia do Direito, GT. № 1: Antropologia nas prisões: sobrecargas de segregações. São Paulo, 2015.

DUARTE, Samuel Correa. A prisão preventiva no sistema

jurídico brasileiro: entre a proteção do acusado e a

antecipação da pena presumida. RBSD - Revista Brasileira de Sociologia do Direito, v. 6, n. 2, p. 40-62, maio/ago. 2019. 